\title{
Health Care Associated Multidrug Resistant Acinetobacter Infections in a Tertiary Critical Care Center of Dhaka, Bangladesh
}

\author{
MF MIA $^{\mathrm{a}}, \mathrm{AAKHAN}^{\mathrm{b}}, \mathrm{ACHAKRABORTY}^{\mathrm{c}}$
}

\begin{abstract}
:
Introduction: Acinetobacter spp, emerged as important pathogen exhibiting increasing antimicrobial resistance. Worldwide, multi-drug resistant Acinetobacter is being established as a significant cause of health-care-associated infections along with their resistant trait.
\end{abstract}

Methods:This retrospective, cross-sectional study was done in critical care centers (CCC) of Combined Military Hospital (CMH) from May to September 2016. Total 69 patients with infection by Acinetobacter were included in this study. Center for Disease Control (CDC) criteria for selection of nosocomial infection were used. Specimen were inoculated in blood and MacConkey agar, incubated 24 hours at $37^{\circ} \mathrm{C}$ in aerobic condition and yield in plates were examined. Antibiotic resistance of isolated organisms were observed in Mueller Hinton agar sensitivity media by using Kirby Bauer disc diffusion method.

Results: Among the total 69 (males 27, females 42,) and age range 2-75 years, Acinetobacter infected patients, 31 were from medical, 23 from surgical and 15 were from high

a. Prof (Lt Col) Dr Md Faruk Mia, MCPS (Lab Med), FCPS (Microbiology), Head, Department of Microbiology and Consultant, Pathology, Ahsania Mission Cancer and General Hospital, Uttara-10, Dhaka.

b. Professor (Brig. Gen.) Arif Ahmed Khan, Armed Forces Advisor Specialist and Head of the Dept. of Microbiology \& Molecularbiology, Deputy Commandant, Institute of Pathology (AFIP), Dhaka Cantt., Dhaka-1206.

c. Lt.Col Dr. Anjana Chakraborty, Classified Specialit in Dermatology and Venereology, CMH Chittagong Cantt., Chittagong.

Address of Correspondence: Prof. (Lt Col) Dr. Md. Faruk Mia, MCPS (Lab Med), FCPS (Microbiology), Head, Department of Microbiology and Consultant, Pathology, Ahsania Mission Cancer and General Hospital, Uttara-10, Dhaka. PH (8802) 8932264 , mob-+8801711283520, 8801769050538 . Email:mdfarukmia@yahoo.com

Received: 16 August 2018

Accepted: 10 January 2020 dependency unit (HDU). Specimens were tracheal aspirate (24, 34.80\%), urine (18, 26.90\%), wound swab $(12,17.40 \%)$, pus (6, 8.70\%), high vaginal swab (6, 8.70\%) and bronchoalveolar lavage (3, 4.35\%). Empiric antibiotics were given in all, one course of antibiotic was used in one, in others two or more courses were given. In the study, total 17 antibiotics were used for identifying resistance pattern of Acinetobacter isolates. Ceftazidime (91.30\%), ceftriaxone (91.30\%), amikacin(52.20\%), gentamicin (33.33\%), cotrimoxazole (50\%) and ciprofloxacin (65.22\%) were mostly resistant. Colistin appeared as most effective antibiotic with only $7.70 \%$ resistance rate.

Conclusion: Acinetobacter, isolated in this study were resistant to most antibiotics. Colistin was the most sensitive one. Multi drug resistance (DR), extended DR and pan DR Acinetobacter organisms are reported worldwide, work on clinical presentation, trends of drug use in particular set up is important to combat the situation of 'Going out of drug state'.

Keywords: Acinetobacter, Drug-resistance, Health-careassociated infections, Colistin.

(J Bangladesh Coll Phys Surg 2020; 38: 59-63) DOI: https://doi.org/10.3329/jbcps.v38i2.45628

Introduction:

Acinetobacter is an aerobic, catalase-positive, oxidasenegative, gram-negative coccobacillus ubiquitous in nature. Twenty three named and 11 unnamed species of the genus Acinetobacter are associated with a specific ecologic niche that shape their genomic contents. ${ }^{1-2}$ In late 1980s, A.boumannii emerged as important pathogen exhibiting increasing antimicrobial resistance. ${ }^{3-4}$ Rapid spread of multidrug resistant A.boumannii was associated with recently acquired ability to incorporate resistance determinants. ${ }^{5-7}$ Multidrug-resistant A.boumannii was identified as important pathogen after traumatic injuries sustained in soldiers during recent 
Middle Eastern conflicts, both environmental contamination during the injury and acquisition during medical care has been proposed as potential sources. ${ }^{8-}$ 10 Worldwide establishment of multidrug-resistant A.boumannii as a significant cause of health-careassociated infections (HAI) coupled with lack of potent antimicrobial agents in phase $2 / 3$ of development, constitutes important public health emergency that need be addressed. ${ }^{11}$

HAI represent the greatest public health impact of Acinetobacter, given the rapid spread of antibiotic resistant strains, continuing acquisition of additional resistance mechanisms. A limited number of widespread clonal lineages of A.boumannii are responsible for hospital outbreaks worldwide. ${ }^{12} A$.boumannii has increased frequency as the cause of HAI pneumonia over the past two decades, to cause between 3\% to $7 \%$ of cases. ${ }^{13,14}$ Among patients requiring mechanical ventilation for more than 5 days, Acinetobacter was the most frequent pathogen in one series, accounting for $26 \%$ of pneumonia. ${ }^{15}$ Acinetobacter causes $1 \%$ to $2 \%$ blood stream infections associated with intravascular catheters, surgical site infections and urinary tract infections. ${ }^{16}$ Less frequent $\mathrm{HAI}$ included meningitis after neurosurgery and wound infections in burn patients. ${ }^{17-}$ 19

A paucity of available drugs to treat admitted patients in the set up of Critical Care Center (CCC) was the inducing impulse to undertake the study to find out the prevalence of Acinebacter and their antibiotic resistance pattern.

\section{Methods and materials:}

This retrospective study was done at Combined Military Hospital (CMH), Dhaka from May to November 2016. During this period, a total of 69 different pathological samples (out of total 570 samples) from 69 patients admitted in CCC revealed nosocomial infection ${ }^{20}$ with Acinetobacter.

Laboratory identification: The collected pathological specimens were transported to microbiology department of Armed Forces Institute of Pathology (AFIP) under aseptic condition and cultured in blood agar, MacConkey agar and chocolate agar (selected samples) in aerobic conditions. Sub-culture in selective media were done in mixed-growth cases. Organisms were identified using conventional techniques: Gram stain, catalase test, oxidase test, motility test by hanging drop preparation and other tests as required.

Antimicrobial sensitivity testing: Antibiotic resistance/ sensitivity of the isolated organism were done in Mueller Hinton agar sensitivity test media by the Kirby Bauer disc diffusion method. ${ }^{21}$ Discs used against the organisms in the study were azithromycin, amoxicillin, amikacin, amoxicillin-clavulanate, cefepime, ciprofloxacin, gentamicin, colistin, meropenem, piperacillin-tazobactum, tetracycline, linezolid, trimethoprim-sulphamethoxazole, nitrofurantoin and nalidixic acid. Results of the culture sensitivity were recorded according to The Clinical and Laboratory Standards Institute (CLSI) standards. ${ }^{22}$

Ethical issue: Due approval was obtained from competent authority [CMH Dhaka, AFIP, Directorate General Medical Services (DGMS)] for the study.

Statistical analysis: Analysis of the results was done by statistical analysis using microsoft excel data analysis package and results were presented in tables and figure.

\section{Results:}

Total 69 samples grew Acinetobacter from 69 patients with female predominance $(42,61 \%)$. Age of the patients were between 2 to 75 years. Most $(31,47 \%)$ Acinetobacter spp. were from medical cases admitted in $\mathrm{CCC}$ with fever of unknown origin (FUO) $(25,36.23 \%)$ and septicemia $(6,8.70 \%)$, followed by surgical and high dependency unit (HDU) (Table I). Tracheal aspirate (24, $34.80 \%)$ and urine $(18,26.90 \%)$ were the two most common specimens that grew Acinetobacter. Others are shown in Table II.

\section{Table-I}

Distribution of Acinetobacter cases $(n=69)$

\begin{tabular}{llcc} 
Department & Syndrome & $\begin{array}{c}\text { Number } \\
\text { of patients }\end{array}$ & Percentage \\
\hline Medical & FUO with shock & 25 & 36.23 \\
& Septicemia & 6 & 8.70 \\
Surgical & Trauma & 9 & 13.04 \\
& Organectomy & 14 & 20.30 \\
\multirow{2}{*}{ HDU } & Device catheter & 9 & 13.04 \\
& Ventilator & 6 & 8.69 \\
\hline & Total & 69 & 100 \\
\hline
\end{tabular}




\section{Table-II}

\begin{tabular}{lcc}
\multicolumn{4}{c}{$\begin{array}{c}\text { Distribution of specimens that grew } \\
\text { Acinetobacter }(n=69)\end{array}$} \\
Sample & Number & Percentage \\
\hline Tracheal aspirate & 24 & 34.78 \\
Urine & 18 & 26.09 \\
Wound swab & 12 & 17.40 \\
Pus & 6 & 8.69 \\
High vaginal swab & 6 & 8.69 \\
Bronchoalveolar lavage & 3 & 4.35 \\
\hline
\end{tabular}

All CCC admitted patients were given antibiotics, in one case one course of antibiotic was used, in other cases two or more were used. In decreasing order they were cephalexin $(29,19.73 \%)$, ceftazidime $(27,17.76 \%)$, meropenem $(21,13.81 \%)$, ceftriaxone $(18,11.84 \%)$, azithromycin $(15,9.86 \%)$, amikacin $(12,7.90 \%)$, gentamicin $(12,7.90 \%)$, cefepime $(9,5.92 \%)$, erythromycin $(6,3.94 \%)$ and colistin(3, 1.97\%) (Table III).

\section{Table-III}

Antibiotics prescribed before receiving culture reports $(n=152)$

\begin{tabular}{lcc} 
Name of drug & $\begin{array}{c}\text { Number of } \\
\text { patients treated }\end{array}$ & Percentage \\
\hline Amikacin & 12 & 7.89 \\
Azithromycin & 15 & 9.87 \\
Cefepime & 9 & 5.92 \\
Ceftazidime & 27 & 17.76 \\
Ceftriaxone & 18 & 11.84 \\
Cefhalexin & 29 & 19.08 \\
Colistin & 3 & 1.97 \\
Erythromycin & 6 & 3.95 \\
Gentamicin & 12 & 7.90 \\
Meropenem & 21 & 13.82 \\
\hline
\end{tabular}

Antibiotic sensitivity and resistance of isolated Acinetobacter spp.(first 23 cases) is shown in Figure 1. Acinetobacter isolated from representative sample in the study are shown along the $\mathrm{X}$ axis and number of sensitive or resistance in particular isolate along the $Y$ axis. Series 1 and series 2 represents sensitive and resistance line chart of the study. The lower small square point of series 1, represent the first isolate at point 1 , where it showed only one drug was sensitive and other 8 drugs were resistant.

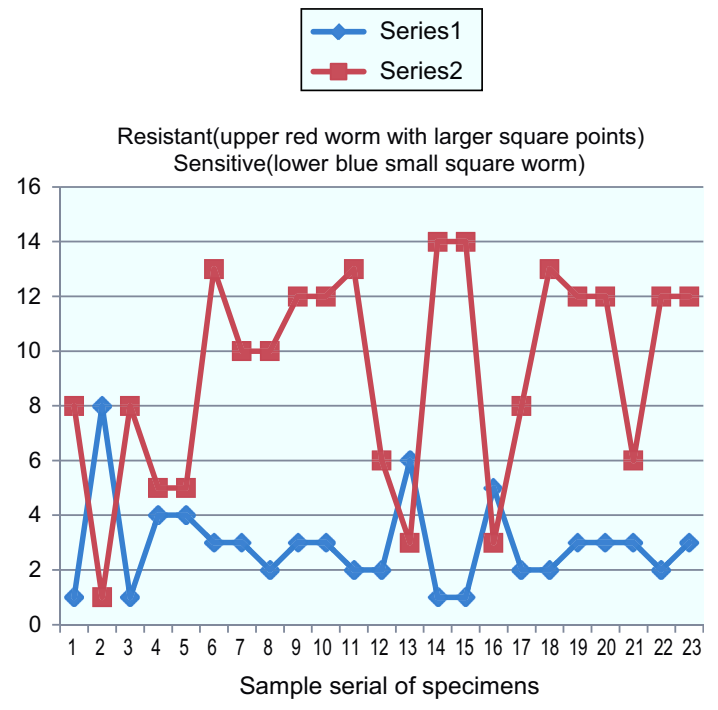

Fig.-1: Acinetobacter spp. with their antibiotic sensitivity/resistance patterns (first 23 cases)

\section{Discussion:}

Acinetobacter was treated as a commensal or colonizer two decades back. With the emergence of drug resistance in the isolated organisms, it is the most isolated nosocomial pathogen with alarming pathogenicity and multi-drug resistant trends. The organism is known as an important and common pathogen causing nosocomial pneumonia and other systemic infections among patients admitted in critical care units (CCUs) worldwide. ${ }^{23}$ Also there are evidence of skin, urinary tract and soft tissue infections by the organism in this study and study by others. ${ }^{24}$ Blood stream infections and secondary meningitis are also reported. ${ }^{25}$ The prevalence is raised in past decadesthat could be related to rising proportion of susceptible population for advancement in care of critically ill and high dependent patients. ${ }^{26}$ The outcomes in patients with Acinetobacter infections appeared poorer if caused by isolates with resistance to multidrug antimicrobial trait. ${ }^{27}$ Surgery, catheterization, mechanical ventilation and antibiotic therapy for aged patients and respiratory distress syndrome, mechanical ventilation and prematurity for pediatric patients were the main factors for Acinetobacter infection in one study. ${ }^{28}$ We found fever with shock and septicemia as main medical causes, trauma and organectomy as main surgical event, while indwelling catheter and patients of coma in ventilator eventually lead to drug resistant nosocomial 
Acinetobacter spp. infection. In the study total fifteen types of antibiotics were used to see the resistance pattern of Acinetobacter isolates and ceftazidime (91.30\%), ceftriaxone (91.30\%), amikacin (52.20\%), gentamicin $(33.33 \%)$, cotrimoxazole $(50 \%)$, and ciprofloxacin $(65.22 \%)$ were the resistant drugs. In a study at a tertiary care hospital in Iran in 2011, researchers found, ceftazidime (96\%), ceftizoxime (95\%), ceftriaxone (93\%), amikacin (58\%), gentamicin (58\%), cotrimoxazole $(85 \%)$ and ciprofloxacin (85\%) were highly resistant. ${ }^{29}$ Extended-spectrum cephalosporinages in Acinetobacter causes their resistance to $3^{\text {rd }}$ and $4^{\text {th }}$ generation ofcephalosporins. In the study vancomycin, levofloxacin were more effective (both only 33.33\% resistant), and colistin was most effective antibiotic.Current Clinical and Laboratory Standards Institute breakpoints for Colistin are $2 \mu \mathrm{g} / \mathrm{mL}$ susceptible and $4 \mu \mathrm{g} / \mathrm{mL}$ resistant. ${ }^{30}$

In the study colistin emerged as the most effective antibiotic against hospital acquired multidrug resistant Acinetobacter infections (only $7.70 \%$ resistance rate) as comparison of the study in which all their isolated species of Acinetobacter were sensitive. ${ }^{31}$

Study limitation: The study was performed in a tertiary level hospital in Dhaka city with a relatively small sample and short span of time.

Conclusion: Identification and susceptibility study of 69 isolates of Acinetobacter from CCC and HAI environment was done in the study, which showed marked resistance to used antibiotics. Work on clinical presentation, trends of drug use in particular set up is of paramount value to overcome the scenario of 'Going out of drug state'.

Acknowledgement: I express deep respect and regards to AFIP, DGMS, and CMH Dhaka authorities for the all out cooperation they rendered for the conduct of the study. I wish to thank my colleagues, technologists and my family members for their cooperation and assistance for the study.

\section{Conflict of Interest: None}

\section{References:}

1. Vallenet D, Nordmann P, Barhe V, Poirel L, Mangenot S, Batailleet et al. Comparative analysis of Acinetobacters: three genomes for three lifestyles. PloS One. 2008; 3:e1805.
2. Visca P, Selfert H, Towner KJ. Acinetobacter infection-an emerging threat to human health. IUBMB life. 2011; 63:1048-1054.

3. Howard A, O'Donoghue M, Feeney A, Sleator RD. Acinetobacter baumannii: An emerging opportunistic pathogen. Virulence. 2012;3(3):243-250.

4. Munita JM and Arias CA. Mechanisms of Antibiotic Resistance. MicrobiolSpectr 2016 Apr; 4(2): 1128.

5. Hasan MJ, Shamsuzzaman SM. Distribution of adeB and NDM-1 genes in multidrug resistant Acinetobacter baumannii isolated from infected wound of patients admitted in a tertiary care hospital in Bangladesh. Malays J Pathol. 2017 Dec; 39(3):277-283.

6. Sahl JW, Gillece JD, Schupp JM, Waddell VG, Driebe EM, Engelthaler DM et al. Evolution of a pathogen: a comparative genomic analysis identifies a genetic pathway to pathogenesis in Acinetobacter. PLoS One. 2013; 8: e54287.

7. Diancourt I, Passet V, Nemec A, Dijkshoorn L, Brisse S. The population structure of Acinetobacter baumannii expanding multi-resistant clones from an ancestral susceptible genetic pool. PLoS One. 2010; 5: e10034.

8. Calhoun JH, Murray CH, Manring MM. Multidrug-resistant Organisms in Military Wounds from Iraq and Afghanistan. Clin Orthop Relat Res. 2008 Jun; 466(6): 1356-1362.

9. Alga A, Wong S, Shoaib M, Lundgren K, Giske CG, von Schreeb J et al. Infection with high proportion of multidrugresistant bacteria in conflict-related injuries is associated with poor outcomes and excess resource consumption: a cohort study of Syrian patients treated in Jordan BMC Infect Dis. 2018; 18: 233.

10. Yun HC, Murray CK, Roop SA, Hospenthal DR, Gourdine E, Dooley DP. Bacteria recovered from patients admitted to a deployed U.S. military hospital in Baghdad, Iraq. Mil Med. 2006; 171:821-825.

11. Manchanda V, Sanchita S, and Singh NP. Multidrug Resistant Acinetobacter.J Glob Infect Dis 2010 Sep-Dec; 2(3): 291-304.

12. CatiaCillóniz Cristina DominedòAntoni Torres. MultidrugResistant Acinetobacter baumannii Emerging Pathogen among Older Adults in Community Hospitals and Nursing Homes, Clinical Infectious Diseases 2010;50(12):16111616.

13. Kollef MH, Morrow LE, Baughman RP, Donald EC, John EM, Jr, Scott TM et al. Health Care-Associated Pneumonia (HCAP): A Critical Appraisal to Improve Identification, Management, and Outcomes-Proceedings of the HCAP . Summit.CID 2008:46 (Suppl 4).

14. Wong D, Nielsen TB, Bonomo RA, Pantapalangkoor P, Luna B, Spellberg B . Clinical and Pathophysiological Overview of Acinetobacter Infections: a Century of Challenges. Clin. Microbiol. Rev. January 2017; 30(1): 409-447, 
15. Rocha LA, Vilela CAP, Cezário RC, Almeida AB, Gontijo Filho P. Ventilator-associated pneumonia in an adult clinical-surgical intensive care unit of a Brazilian university hospital: incidence, risk factors, etiology, and antibiotic resistance. Braz J Infect Dis 2008;12 (1): Salvador Feb. 2008.

16. Langeveld VI, Gagnon RC, Conrad PF, Gamelli RL, Martin B, Choudhury MA et al. Multiple-Drug Resistance in Burn Patients: A Retrospective Study on the Impact of Antibiotic Resistance on Survival and Length of Stay. J Burn Care Res. 2017 Mar/Apr;38(2):99-105

17. Guggenbichler JP, Assadian O, Boeswald M, Kremer A. Incidence and clinical implication of nosocomial infections associated with implantable biomaterials - catheters, ventilator-associated pneumonia, urinary tract infections. GMS Krankenhaushy gieneinter disziplinär. 2011; 6(1):Doc 18.

18. Weber DJ, Duin DV, DiBiase LM, , Hultman CS, Jones SW, Lachiewicz AM et al. Healthcare-Associated Infections among Patients in a Large Burn Intensive Care Unit: Incidence and Pathogens, 2008-2012. Infect Control Hosp Epidemiol. 2014 Oct; 35(10): 1304-1306.

19. https://www.cdc.gov/hai/infection types.html

20. Julia SG, Willium RJ, Emori TG, Theresa CH, James MH.CDC definitions for nosocomial infections, 1988.

21. Guardado AR, Blanco A, Asensi V, Pérez F, Rial JC, Pintado $\mathrm{V}$ et al. Multidrug-resistant Acinetobacter meningitis in neurosurgical patients with intraventricular catheters: assessment of different treatments.Journal of Antimicrobial Chemotherapy 2008;61(4): 908-913.

22. Lunenfeld B and Pamela SP. The clinical consequences of an ageing world and preventive strategies Best Pract Res Clin Obstet Gynaecol. 2013 Oct; 27(5): 643-659. Published online 2013 Mar 28.
23. Chopra T, Marchaim D, Awali RA, Krishna A, Johnson P, Tansek R et al. Epidemiology of Bloodstream Infections Caused by Acinetobacter baumannii and Impact of Drug Resistance to both Carbapenems and Ampicillin-Sulbactam on Clinical Outcomes. Antimicrobial Agents and Chemotherapy. 2013; 57(12):6270-6275.

24. Wroblewaka MM, Dijkshoorn I, Roop SA, van den Barselaar M, Swoboda-Kopec E, van den Broek PJ et al. Out-break of nosocomial meningitis caused by Acinetobacter boumannii in neurosurgical patients. J Hosp Infect. 2004; 57: 300-307.

25. Lin M-F, Lan C-Y. Antimicrobial resistance in Acinetobacter baumannii: From bench to bedside. WJCC. 2014; 2(12):787814.

26. Anton Y, Seifert PH, Peterson DL. Acinetobacter baumanni: Emergence of a Successful Pathogen. Clin Microbiol Rev. 2008 Jul; 21(3): 538-582.

27. Sultan AM, Saliem WA . Identifying Risk Factors for Healthcare-Associated Infections Caused by CarbapenemResistant Acinetobacter baumannii in a Neonatal Intensive Care Unit. Sultan Qaboos Univ Med J. 2018 Feb; 18(1): e75-e80.

28. Vahdani P, Yaghoubi T, Aminzadeh Z. Hospital Acquired Antibiotic Resistant Acinetobacter boumannii Infections in a 400-Bed Hospital in Tehran, Iran. Int J Prev Med. 2011 Jul-Sep; 2(3): 127-130.

29. Rodriguez MJM, Nordmann P, Roncho E, Poirel L. Extended-spectrum cephalosporinase in Acinetobacter boumannii. Antimicrob Agents Chemother. 2010; 54: 3484 3488 .

30. Fishbain J, Anton YP. Treatment of Acinetobacter Infections, Clinical Infectious Diseases 2010; 51(1):7984.

31. Sinirta_ M. Investigation of colistin sensitivity via three different methods in Acinetobacter baumannii isolates with multiple antibiotic resistance. September 2009; 13(5): e217-e220. 